\title{
Hijab as a Muslim Attire and a Fashion Trend in Bangladesh
}

\author{
Mubina Khondkar \\ Professor, Department of Marketing, University of Dhaka, Dhaka 1000, Bangladesh
}

\begin{abstract}
This research focuses to understand the driving forces behind wearing hijab. It investigates hijabistas' buying behavior and identifies reasons for its increased demand in Bangladesh. It analyzes data using consumer buying behavior concept as the theoretical framework. Descriptive research design is used to collect qualitative and quantitative empirical data. A sample of 100 Bangladeshi women who wear hijab are selected as respondents using convenience and snowball sampling techniques. Personal interview and online survey are used to collect data. Increase in Islamic followers has increased Islamic consumerism. Traditionally, Muslim attire is worn to conform to religious values. In the last decade, hijab became popular Muslim attire as a part of not only religion but also fashion statement. Fashion consciousness with religious imprints, impacts of influencers and opinion leaders through social media, a means of enhancement of beauty, and globalization have positive causal relationships with growing popularity of hijab in Bangladesh. Acceptance of hijab has been increased by global brands as they incorporated various marketing strategies along with introduction of hijab in their product line.
\end{abstract}

Keywords: Bangladesh, Hijab, Hijabista, Hijab buying behavior, Hijab fashion trend, Muslim attire

DOI: $10.7176 / \mathrm{EJBM} / 13-3-08$

Publication date: January $31^{\text {st }} 2021$

\section{Introduction}

Hijab is a piece of cloth or headscarf or veil worn by a woman on head to cover hair and neck. Wearing hijab usually is guided by her religion and/or culture to seclude her from men outside of her family. Hijab is an Arabic word and the literal meaning of it is to veil, to cover, and to screen. It came from the word ' $h a-j a-b a$ ' which means 'to veil' and 'to cover' (El Guindi, 2003). The English word scarf and the Arabic word hijab are often used interchangeably but hijab has some cultural connotations. Concepts of veil are linked to both women and men (El Guindi, 2020). Most Arab men wear a keffiyeh or shemagh, a cotton scarf, which they put on head using a strong cord, called agal, to hold it tight in place (Sonbuol, 2017). Men in arid regions of the Middle East cover their head and body to get protection from direct sun exposure to avoid sunburn, and to reflect heat of the sun to stay cool. In cooler weather they wear heavier headdresses to stay warmer, and sometimes they also cover face to protect the mouth and eyes from dust and sand. Therefore, it might be argued that the concept of covering body and especially head might have been originated from a perception of enhancing protection against adverse climatic conditions which gradually been copied in other countries.

Bangladesh is a moderate Islamic country; wearing hijab is not compulsory here and it is seen both as a matter of compliance to religious norms and as a style. Wearing hijab is a religious and cultural practice to express identity and spiritual belief (Galadari, 2012). A woman who fashionably wears hijab along with complying with religious obligation is known as Hijabista (Bloomaert and Varis, 2015). The word hijabista comes from two words - hijabi and fashionista (Kavakci and Kraeplin, 2016). Hijab is a symbol of Muslim women and it visibly differentiates them from non-Muslims. However, these days senses around hijab and the person who wears it have also created stereotyped notions (Irfan, n.d.). The modern hijab trends allow Muslim women to stay modest by blending selfexpression with latest trends in fashion. Wearing hijab demonstrates cultural and religious value and allow to continue being fashion-conscious within the boundary of Shariah (Fatema and Islam, 2014). Muslim perception about hijab and its design has been gradually transformed by fashion trends. Muslim women follow Islamic dress code while enjoying hijab as a fashion element and Islamic cosmopolitanism allows them to express their individuality through the latest fashion trends with a variety of styles, accessories, and bold colors (Potts, 2009). With the expanding global fashion industry and marketing initiatives, hijab has adopted many fashions, trends, styles, labels, and brands. Hijab fashion has evolved to include Muslim women in the mainstream style, but the factors that influence hijab fashion besides religion have yet to be discovered. Information is now easily accessible through social media and other technology supported means, and modern Muslim women can remain up to date with latest trends. In recent decades, number of hijab users has increased, and it has become a fashion trend.

\section{Objectives}

Only a few studies could be found that have researched on hijab adoption in Bangladesh. This research paper aims to address this dearth of literature. General objectives of this research are to explore purposes of wearing hijab and to identify the associations between religious purposes and/or fashion purposes of wearing a hijab. Three specific objectives are set to fulfill those general objectives.

(1) To identify the factors that influence hijabistas' hijab buying behavior. 
(2) To examine the factors that influence hijab fashion consumption.

(3) To identify the reasons for the growth of hijab industry in Bangladesh.

\section{Methodology}

A descriptive research design is used for this study to collect empirical data for qualitative and quantitative analysis. The research process is structured into two phases, interviewing is used in the first phase and online survey is used in the second phase. In this qualitative dominant mixed method approach, qualitative research precedes to develop an understanding of the phenomenon so that quantitative survey could be effective. This research involves both primary and secondary data. Secondary data are collected from sources including articles, books, reports, newspapers, and other related documents. Two types of nonprobability sampling techniques - convenience sampling technique and snowball sampling technique - are used to select respondents. A sample survey is conducted for collecting primary data. A sample of 100 Bangladeshi women aged between 16 and 60, who wear hijab, are the respondents. The respondents are heterogeneous implying individual differences and indicating a wide spectrum in terms of educational qualification, age, and marital status. Five respondents have degree in medicine, 37 have master's degree, 30 have bachelor's degree, 18 are undergraduate level students, and 10 have school level education. Therefore, $72 \%$ of the respondents are graduates and $28 \%$ are below the level of graduation. Among the respondents, $6 \%$ are less than 20 years old, $46 \%$ are $20-40$ years old, and $48 \%$ are $40-60$ years old. In terms of marital status, $74 \%$ are single while $26 \%$ are married among the respondents. Personal interview and online survey methods are used to collect primary data. Statistical tools are used for quantitative analysis and thematic analysis is used for qualitative analysis.

\section{Hijab Buying Behavior}

Islam is one of the ancient and rapidly grown religions in the world (Dagkas and Benn, 2006). Different society and regions adopted different Muslim clothing based on the principles of modesty. Hijab is one of the iconic identities of Muslim women symbolizing privacy and modesty (Rita, 2017). Fashion consciousness is a person's interest in the latest fashion (Nam et al., 2007). Fashion-conscious consumers strive to adopt the latest style (Gutman and Mills, 1992). Out of 1.8 billion Muslims in the world, there are more women than men, and almost half of the Muslim women wear hijab. With the greater outreach of social media and widespread awareness, hijab culture has been transformed into a fashion and style-oriented megatrend. Muslim women, especially young girls, tend to look for a new trendy hijab and attire with different color schemes based on aesthetic senses. This trend of fulfilling the religious obligation along with adopting new and stylish trends in hijabs has been flourishing at a fast pace.

The word hijab denotes modesty, virtue, and respect (Siraj, 2011). Hijab often is defined as an instrument of empowerment, a fashion statement, and a form of expression of one's personality. The various meanings of hijab have revealed various themes. In the Muslim context, wearing a hijab that cover's a woman's hair, neck, and ears is a religious obligation for Muslim women. However, wearing hijab is more than just covering one's hair; it symbolizes modesty, morality, natural beauty, and the harmonious interactions between a Muslim woman and the society. In some perspectives, hijab refers to a partition and curtain in literal and metaphorical senses. Muslim women, residing in countries where wearing hijab is not compulsory and in non-Muslim countries, often wear hijab to show their Islamic consciousness and revival trend (Stacey, 2009). Hijabistas' hijab buying behavior is guided by attributes of it that satisfy their need for wearing fashionable clothing. Apart from buying a product for its functional attributes, they also make the buying decision based on the symbolic representation and image demonstrated by wearing it (Hassan and Harun, 2016). Hijab buying behavior also depends on symbolic representation and social image of wearing a hijab. They seem to look for a hijab that conveys their values and their intended fashion and style statements. While buying hijabs women exhibit conscious behavior regarding their social status and self-perception (Hassan and Harun, 2016). They want to gain acceptance of the society and so look for related style orientations in the hijab (Hassim, 2014). Young Muslim women are more aware of the latest fashion trends and it impacts their hijab buying behavior.

Some women in Bangladesh wear a hijab to protect hair from air pollution (Dhaka Tribune, 2020). The human body, skin, and hair are exposed to air pollution; and the part most vulnerable to get damaged is hair. Air pollution is the most discussed type of environmental pollution that affects quality of air due to contamination and is usually caused by smoke and harmful gases. Even head of World Health Organization (WHO) has warned that air pollution is supposed to be considered as the new tobacco (Carrington and Taylor, 2018). Dust, dirt, fume, smoke, and gases can cause scalp irritation, dryness, breakage, unexpected hair fall, premature baldness; and doctors often recommend covering head in case of scalp diseases. As Dhaka is one of the most polluted cities in the world and has the worst air quality, some women trust that hijab protects their hair from air pollution (Dhaka Tribune, 2020).

\subsection{Hijab as a Muslim Attire}

Modest clothing has two types, head coverings and body coverings. The most popular head covering is hijab which 
sometimes includes Nikab - a face covering. Common body coverings include burkha, jilbab, abaya, and manteau; all of these are loose-fitting full sleeve gown, a kind of overcoat traditionally restricted to be in black (Ali, 2005; Al-Ardhi, 2008). In some Muslim countries, such as in Egypt, wearing Muslim attire started during the 1970's Islamic movement (El Guindi, 1999). According to some researches, discussions of Islamic culture and consumption of Islamic garments started during the 1990s (Almila and Inglis, 2019). Over time Muslim attire has gone through drastic changes both in terms of color and design. Muslim women wear Muslim attire due to the Islamic belief that it is their spiritual obligation (Ali, 2005). Many of them are motivated to wear Islamic attire advocated by the holy Quran and hadith, their families, friends, and media (Ali, 2005; Genel and Karaosmanoglu, 2006; Al-Ardhi, 2008). Some find wearing hijab as a worthy practice because hijab offers them shields and protections (Ali, 2005). Some also wear hijab for their religious beliefs as well as out of their fashion consciousness (Rahman, et al., 2018). Perception of hijab varies among users and non-users; while users perceive it as a religious dress code, the non-users perceive it as an unnecessary piece of clothing (Siraj, 2011).

\subsection{Hijab as a Fashion Trend}

Fashion is an aesthetic expression of individualism in clothing, footwear, accessories, and hairstyle. It is an element of culture that defines identity of consumers and portrays their social characters. Islamic-oriented content is appearing in media due to globalization and it is an evidence of the evolving lifestyle of Muslim consumers in the Middle East, Europe, and Asia (Cardoso, et al., 2010). The free flow of information technology and extensive media attention are influencing the increased trend of wearing hijab (Hassim, et al., 2017; Lewis, 2013). Media is utilizing its tools to influence women to wear hijab (Latiff and Alam, 2013). Moreover, marketers are also getting interested in this market. Bloomberg estimates that global Muslim fashion market is worth USD96 billion which is backed by the 800 million Muslim women, about $40 \%$ of whom are 25 years old, around the world who are ready to demand and consume related products (Wilson, 2014). As young consumers are inclined to wear fashionable outfits and this global Muslim fashion market expects capitalizing on the longer consumer lifetime. Muslim women usually believe that wearing hijab signifies their symbol of freedom and have gradually changed perspectives of the societies and politics toward Islam and the symbolic nature of hijab (Hassim, 2014; Irfan, n.d.). Muslim women can remain fashion-conscious within the Shariah boundaries (Fatema and Islam, 2014). In Algeria, Egypt, and Turkey, hijab is used as a symbol of freedom from colonial oppression. However, hijab in some other Muslim countries is considered as a symbol of oppression and/or suppression. For instance, Muslim women in Morocco choose hijab due to persuasion instead of tradition; and for them, it is an expression of identity (El Guindi, 1981; Cinar, 2005; Fanon, 1965).

Muslim women are conscious about their self-image and social identity, and this has considerable influence over their consumption. Non-traditional media such as the internet, social media, fashion shows, blogs and vlogs play substantial roles in shaping hijab fashion consumption. Media commercialized hijab fashion in a planned way (Latiff and Alam, 2013) and media often try to demonstrate relationships between 'beauty and modesty' and 'fashion and faith' among hijab users (Tarlo, 2010). Sources of fashion information, dressing vogue, fashion motivation, and fashion uniqueness influence fashion consciousness and consequently inspire hijab fashion consumption (Hassan and Harun, 2016). Fashion industry has been positively shaped by technology and globalization enabling designers to communicate creative ideas and fashion thoughts (Fernandez, 2016). New fashion concepts promote an innovative pattern of changed Muslim identity stretching the dimensions of Islamic fashion (Tarlo, 2020). Globalization motivates Muslim women and even little girls believe that hijab may be helpful for them to create a personal identity (Al-Ardhi, 2008). Many women also consider full covered attire as a protection of skin in summer along with senses of fashion (Ali, 2005). Some fashion designers creatively plan and execute designs of women's clothing incorporating modest looks (Kavakci and Kraeplin, 2016). There exist mix and match creations with local and western trends. Some brands in the UK started to stock up modest clothing while many attire companies in the USA have been inspired to design and produce clothes following Islamic philosophy (Wilson and Liu, 2011). Local and global brands and fashion houses organize fashion shows, hire wellknown models to promote fashion trends of Islamic attires, and thus local producers become familiar with new fashion trends of Muslim attire (Genel and Karaosmanoglu, 2006). 


\subsubsection{Fashion Consciousness}

Fashion-conscious consumers are usually interested in fashion and style (O'Cass et al., 2013). Fashion consciousness is a person's awareness of fashion, enthusiasm about image and pjysical attractiveness, and ability to dress accordingly (Wan, et al., 2007; Milewski, 2005). These consumers are aware and concerned about their appearance and try to stay in style (Gutman and Mills, 1982). They behave in similarly, pay attention to new trends and styles, tend to engage in images and fashion ideas presented in advertising, try to update their collection of outfits, enjoy shopping and regularly buy clothes of recent trends (Wan, et al., 2007). Fashion-conscious Muslim consumers recognize themselves with symbolic Muslim identity, portray their images through attire, and tend to buy fashionable hijab (Hassan and Harun, 2016). Therefore, they try to communicate their social, cultural, and religious identities through hijab fashion.
Figure 1: Cultural Integration of Hijab

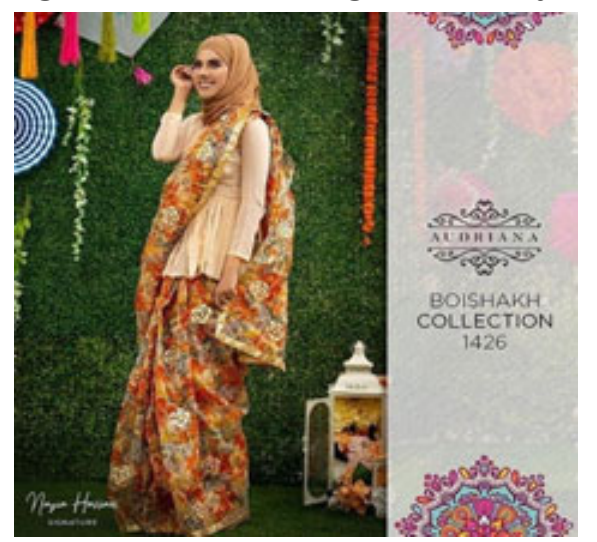

Source: Audriana, 2020

\subsubsection{Fashion Information}

Consumers try to reduce risks in purchase decision making by gathering information about products and services (Koç et al., 2019). Fashion information is usually gathered from personal sources such as friends, family, and siblings; impersonal sources such as traditional mass media advertisements, sales promotions, store displays, agents and/or middlemen; and non-traditional media communications (Schiffman and Kanuk, 2012). Consumers often gather information from the people they admire i.e. reference groups (Kinley, et al., 2000). Fashion-conscious consumers look for information about the latest fashion trends (Hassan and Harun, 2016; Nam et al., 2007). The time and effort spent on searching for fashion information build an attachment and a relationship between consumers and the fashion (Cardoso, et al., 2010). Fashion-conscious consumers depend more on information from mass media (Ibrahim, et al., 2011). In Bangladesh, sources of fashion information for new trends are store displays, fashion magazines, catalogs, digital web sources, social get-together, and reference groups. Consumers with fashion knowledge tend to be more fashion-conscious and usually they are more motivated to celebrate the cultural festivity. Figure 1 presents an advertisement where hijab fashion is integrated with the local cultural festival of Pahela Boishakh (Bengali new year).

\subsubsection{Fashion Motivation}

Motivation becomes the reason behind want for a product and shapes purchase behavior (Bohdanowicz and Clamp, 1994; Mullen and Johnson, 1990). It identifies the behaviors guided by cognition, noncognitive aspects, and both (Hassan and Harun, 2016). Consumers express their identity to others in terms of their symbolic and expressive meanings through the clothing they wear (Hawkins and Mothersbaugh, 2010). The normative influence on fashion for an individual is important in the sense that choice of fashion needs to be liked by their peers (Auty and Elliott, 2001). Fashionconscious consumers are motivated by fashion (Hassan and Harun, 2016), and through apparel choice consumers sometimes find utility and personal enjoyment (Nam et al., 2007). Some fashion bloggers, YouTube influencers, and Instagram influencers and opinion leaders motivate young girls and

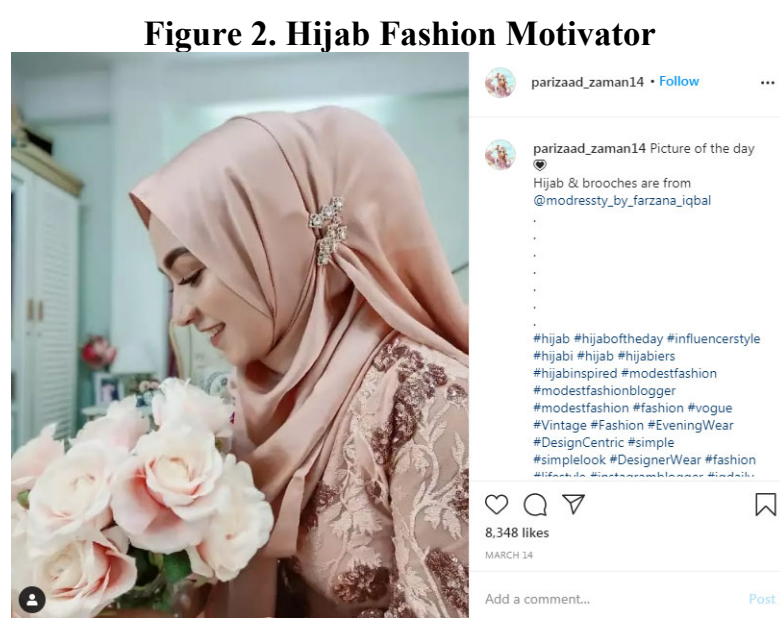

Source: Zaman. 2020 women towards fashion. For example, Parizaad Zaman (Figure 2) is known for her hijab tutorial videos on YouTube, and she motivates young girls towards hijab fashion consumption.

\subsubsection{Fashion Uniqueness}

Fashion uniqueness is the outcome of the desire for uniqueness and from a consumer behavior perspective, 
uniqueness is the potential of consumers to prefer unique products (Tian et al., 2001). To maintain a unique identity, consumers need to uphold uniqueness and for this they need to buy unique goods, services, and experiences (Lynn and Harris, 1997). Importance of uniqueness is more prominent in high-involvement products such as clothing, shoes, and accessories than in low-involvement products, because the former is mostly consumed publicly and serve as a critical means of self-expression (Jin and Son, 2013). When consumers identify that their degree of uniqueness is inadequate then they try to engage in consumption activities like shopping for fashionable clothing (Burns and Warren, 1995). Modern Muslim women have become innovative in their dressing styles through understanding the idea of dressing in Islam and by constructing religious and social representations of Muslim identity (Mossiere, 2012). Fashion-conscious consumers are identified as exclusivity seekers (Hassan and Harun, 2016), and modern Muslim women seek exclusivity in their fashion attire to get identified as fashion conscious because fashion consciousness and fashion uniqueness are correlated.

\subsubsection{Fashion Influencers}

Individual trait and personality are reflected through an individual's attire. When consumers start consistently following an attire style, they become a member of that style community. Members of a style community are individuals who dress similarly and usually think alike. Shops, retailers, designers, and brand houses can be considered as opinion leaders of a style community when they are linked to a signature style that appeals to consumers. As members of a style community, consumers sometimes follow someone they adore and their dressing style. For instance, The Great British Bake-Off winner in 2015 Nadiya Hussain wears hijab; she is a popular chef, writer, presenter, and columnist (Hussain, 2020b). She is active on social networking sites and can be identified as a hijab fashion influencer. Figure 3 presents Nadiya Hussain who is also a brand ambassador of a popular jewelry brand Swarovski.

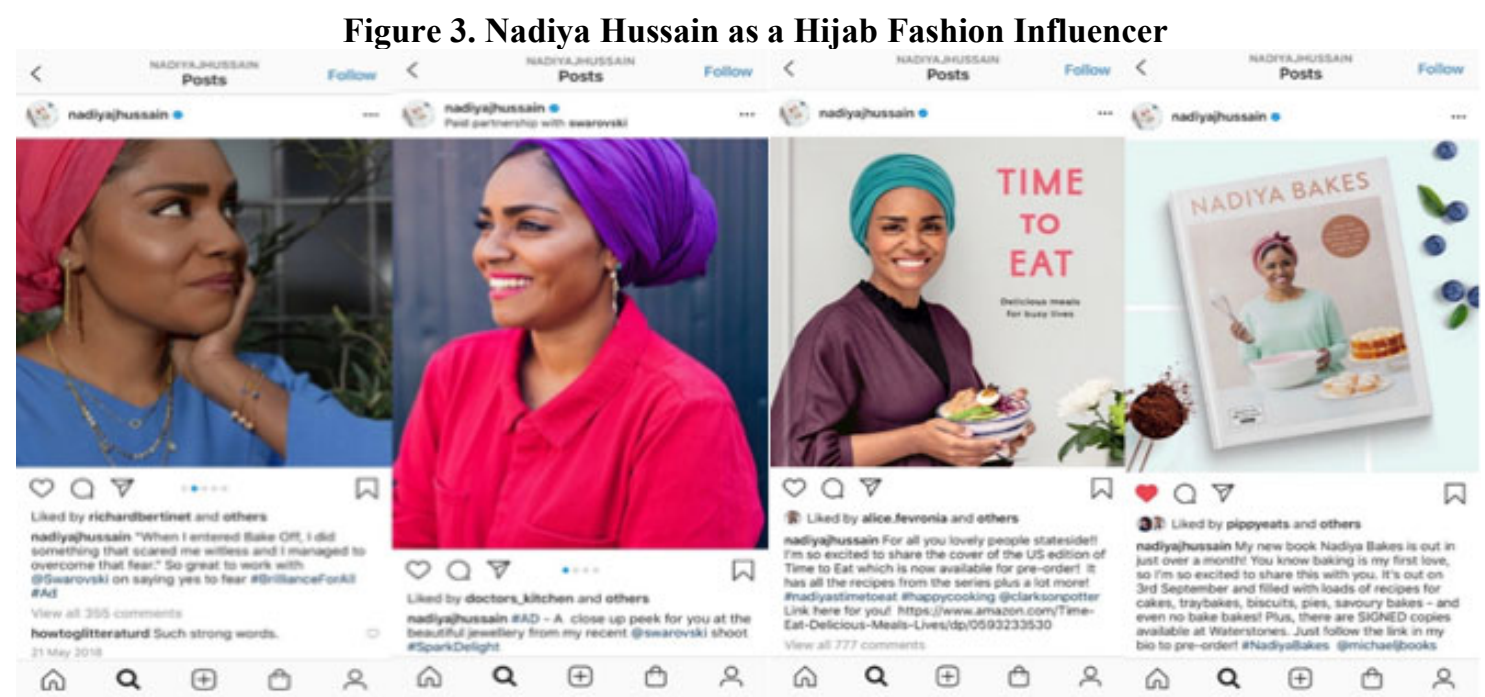

Source: Hussain, 2020a

Interpretations of style may vary from consumer to consumer due to their idiosyncrasy (Hassan and Harun, 2016). Choices of clothing and how these choices complement individual's traits and styles reflect individual's self-concept (Piacentini and Mailer, 2014). So, attire style can be regarded as a powerful tool for improving selfimage. Consumers who have a concern for their attire style are considered conscious about fashion and so attire style and fashion-consciousness are positively related (Wan, et al., 2007). Bloggers and vloggers can influence the idiosyncrasy of consumers through their intimate links to attire style and fashion-consciousness. Among hijabi 
bloggers, Saufeeya Goodson, Heba Jalloul, Ascia al Faraj, Imane Alasry, Dalal AlDoud, Melanie Elturk, Mariah Idrissi, Dina Torkia, Hanan Tehaili, and Habiba da Silva are top ten hijab fashion bloggers followed by hijab enthusiasts (Ehren, n.d.). Top ten global hijab influencers of 2019 are Saudah Saleem, Hakeemah, Sana Ishaq, Fatima, Lauleh, Marwa Meme Biltagi, Aysha Harun, Dr. Noor, Shah Hatun, and Dr. Aisha Sindhu (Mostafa, 2020). In Bangladesh, there are several hijab influencers whom young women adore and follow. One of those influencers is Navin Ahmed (Figure 4), the owner of Gala Makeover Studio \& Salon, who creates interest captivating fashionconsciousness to impact attire style through physical and virtual

Figure 4. Hijab Fashion Influencer

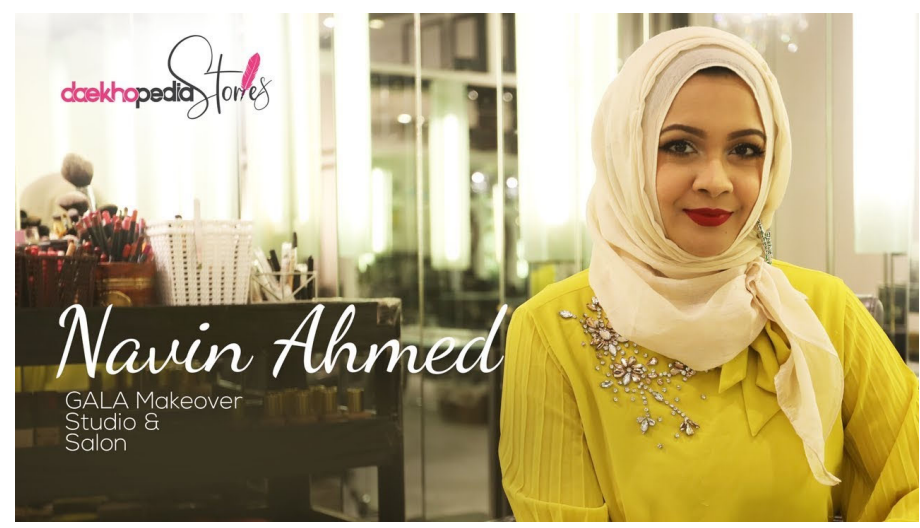

Source: Ahmed, 2020 presences.

\subsection{The Modest Fashion Industry and the Global Brands}

Global Islamic economy is expanding fast with about USD270 billion spent on modest fashion in 2017 which is forecasted to reach USD361 billion in 2023 (Thomson Reuters, 2018). Global Muslim population was 1.8 billion in 2017 and it is projected to reach 3.0 billion in 2060 (ibid). Among the top 10 modest fashion countries, United Arab Emirates (UAE) is ranked first while Bangladesh is ranked ninth (ibid). Modest fashion is entering into the mainstream - from luxury brands to simple high street retailers are now launching modest fashion lines (Posts, 2018; Lifestyle, 2018; Macy's, 2020; Nike, 2017; Gordon, 2018). Models in hijabs are now appearing in advertisements, participating in catwalks, and appearing on cover pages of highly esteemed fashion magazines (Vogue, 2020; Vogue, 2018). American Eagle started to sell denim hijabs in 2017; Swedish clothing brand H\&M released a modest fashion line named LTD Collection in May 2018; Marks \& Spencer from the UK, and Macy's and Michael Kors from the USA have launched modest clothing labels in 2018 (Posts, 2018;

Figure 5. Dolce \& Gabbana's collaboration

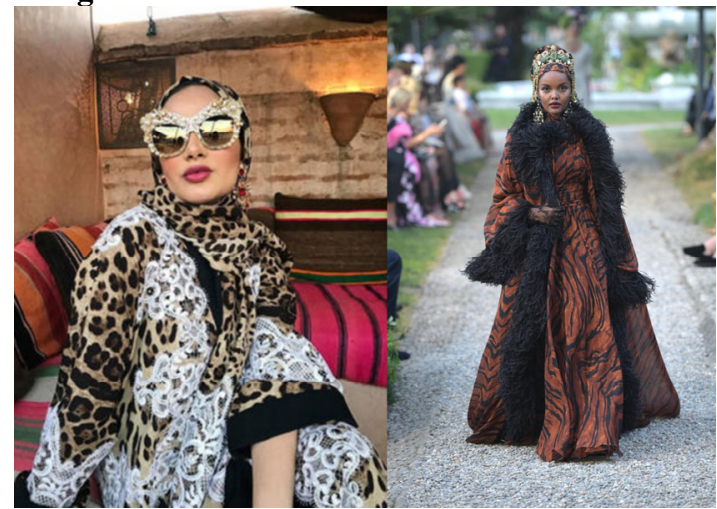

Source: Posts, 2018; Lifestyle, 2018 Glamour, 2018; Glamour, 2017). Italian fashion house Dolce \& Gabbana is promoting modest fashion and is collaborating with hijab influencer Ruba Zai, and the hijab model Halima Aden in the spirit of respecting all religions, cultures, and tradition (Posts, 2018; Lifestyle, 2018). In Figure 5, the left photo shows Ruba Zai in Morocco and the right photo shows Halima Aden at a fashion show near Lake Como in Italy both in Dolce \& Gabbana attires. 
Modest fashion brands are also launched in the Organization of Islamic Cooperation (OIC) countries and world's first modest fashion shopping center was opened in Istanbul in May 2018 (Posts, 2018). In Figure 6, the leftmost image presents hijabs from H\&M, the second left image presents hijab from Michael Kors's, and the two images on the right present Macy's Verona Collection of hijabs.

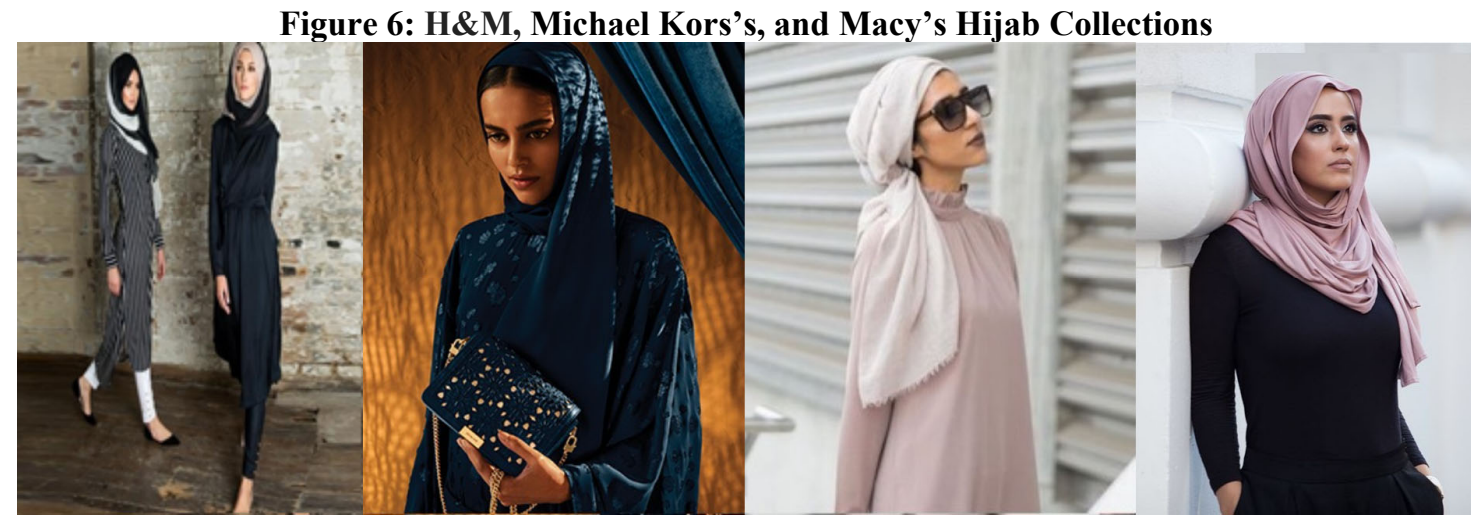

Source: Gordon, 2018; Posts, 2018; Macy’s, 2020

Online-based retailers and influencers have facilitated the initiatives of these global brands to create acceptance and expand the market of modest fashion. Models in hijab now appear in the Cosmopolitan Netherlands and Vogue magazine in the UK and other countries. Modest fashion is gaining more coverage in mainstream media and in online platform. Neelofa is the first hijabwearing ambassador of the beauty brand Lancôme. In Figure 7 four cover pages of Vogue are presented where special personalities in hijab are showcased. The first cover of British Vogue featuring model Halima Aden in a hijab published in May 2018 was a predominantly significant breakthrough of inclusion in the fashion world. In that cover page nine models were featured and identified as new frontiers of changing the face of fashion and Halima Aden in hijab was one of them (Vogue, 2018). She became the first hijabi sports icon in the Sports Illustrated (Okwodu, 2019). Halima Aden, Ikram Abdi Omar, and Amina Adan are portrayed wearing hijab on the covers of Vogue Arabia in 2019. Vogue Arabia featured hijabi Malaysian singer Yuna in 2017 to portray diversity (Vogue, 2017). British Vogue in its July 2020 issue featured essential workers during this Covid-19 pandemic and one of them was Anisa Omar in hijab who is a supermarket assistant at Waitrose in London (Vogue, 2020).

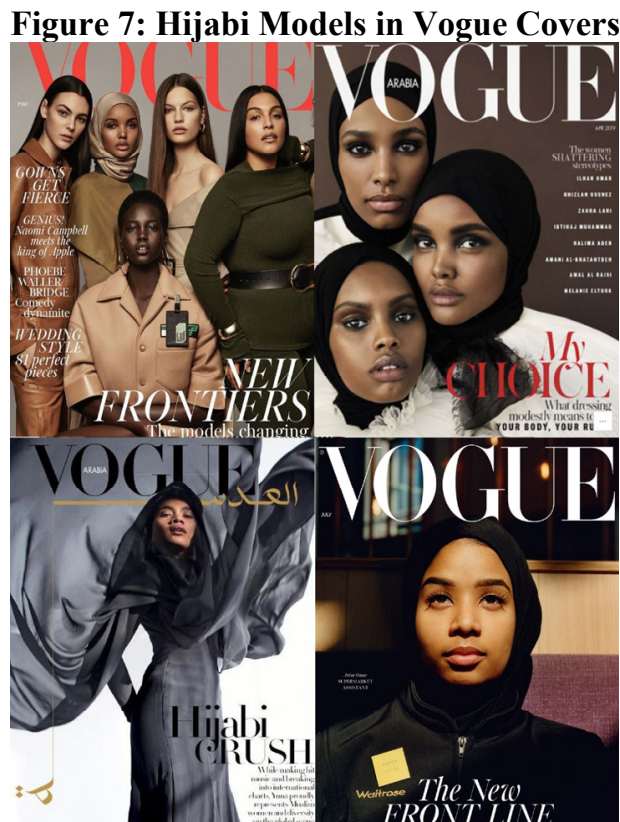

Source: clockwise from top left - Vogue, 2018, 2019, 2020, 2017

Globalization enhanced interactions and integrations among individuals, companies, cultures, and governments of nations. As a result, global brands incorporate these interactions and integrations through various marketing strategies to retain their success in this globalized reality. For example, in 2017 Nike the well-known sportswear company introduced a sports hijab product line with the tagline - the Nike pro-hijab goes global - which is presented in Figure 8. The sportswear giant Nike attempts to expand its market by introducing a high-performance hijab to encourage Middle Eastern women to get involved into sports. 
New Jersey native Ibtihaj Muhammad a Nike athlete and champion fencer, New York Marathon runner Manal Rostom a Nike Run Club Coach in Dubai, and Zeina Nassar a German boxer shared their stories about hijab to popularize Nike hijab (Nike, 2017). The goal was to encourage Muslim women athletes with the groundbreaking products. Nike has always been known as an innovative company and this move is no exception to that. It aims to pioneer inspiring Muslim girls and women to overcome barriers and get access to sports. This push for such a new product introduction was a marketing strategy to expand their market, but it implies far beyond sportswear marketing to encourage

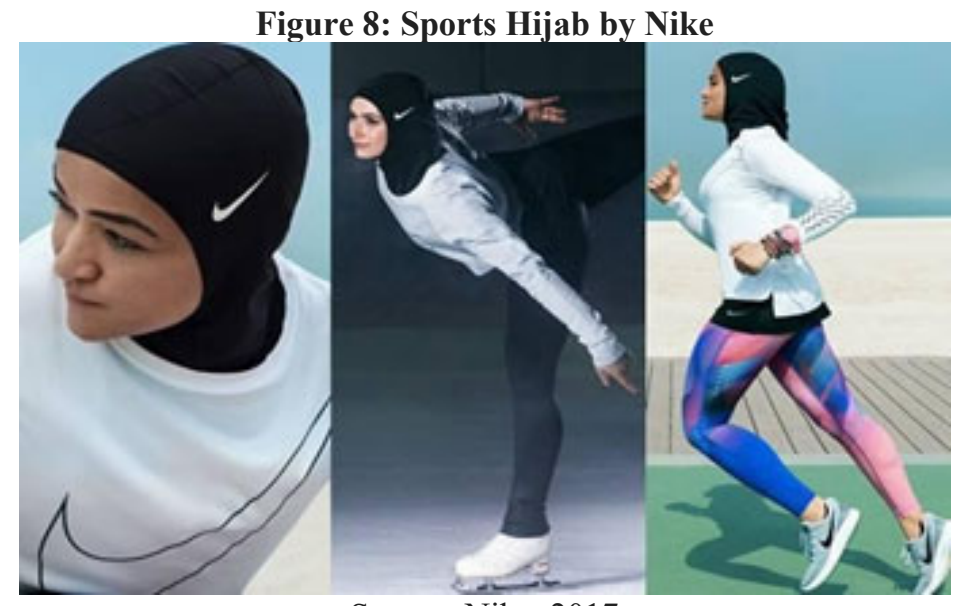

Source: Nike, 2017 gender equality and when such a powerful brand takes such a bold step, it draws social attention as well.

\section{Hijabistas' Buying Behavior in Bangladesh}

This research found that abilities, attitude, attribution, perception, learning, culture, and motivation influence hijabistas' hijab buying behavior. Some significant factors that influence hijab buying decision making are a variety of cognitive biases; an escalation of devotion towards religion; individual differences including educational qualification, age, and marital status; and personal relevance. The research identified opinions and experiences of the hijabistas.

\subsection{Reasons for Wearing Hijab}

Research shows that $91 \%$ of the respondents wear hijab to affirm their Muslim identity and to demonstrate that they are different from non-Muslims. Senses of identity as a Muslim as a means of differentiation is therefore quite strong among the respondents. Although these women are religious-minded, they are open to get influenced by the peer groups and reference groups they admire. As a result, they are always eager to follow the community trend of wearing a hijab. Among the respondents, $6 \%$ wear hijab because they find it nice and fashionable but for them religious dress code ethos is an auxiliary cause for wearing hijab. Only $2 \%$ wear hijab due to peer pressure because their friends wear hijab and they want to be a part of the group by creating acceptance through their similarity in attire. Only $1 \%$ wear hijab for both maintaining religious ethos and becoming a part of today's fashion. This implies that there are people who believe that religion and fashion both are the reasons for wearing hijab, but it is also evident that they are not big in number. Absence of explicit inclusion of fashion senses in traditional religious discourses might be a reason for this trend. Figure 9 presents relative prominence of the different reasons for wearing hijab.

Figure 9: Why do Women Wear Hijab?

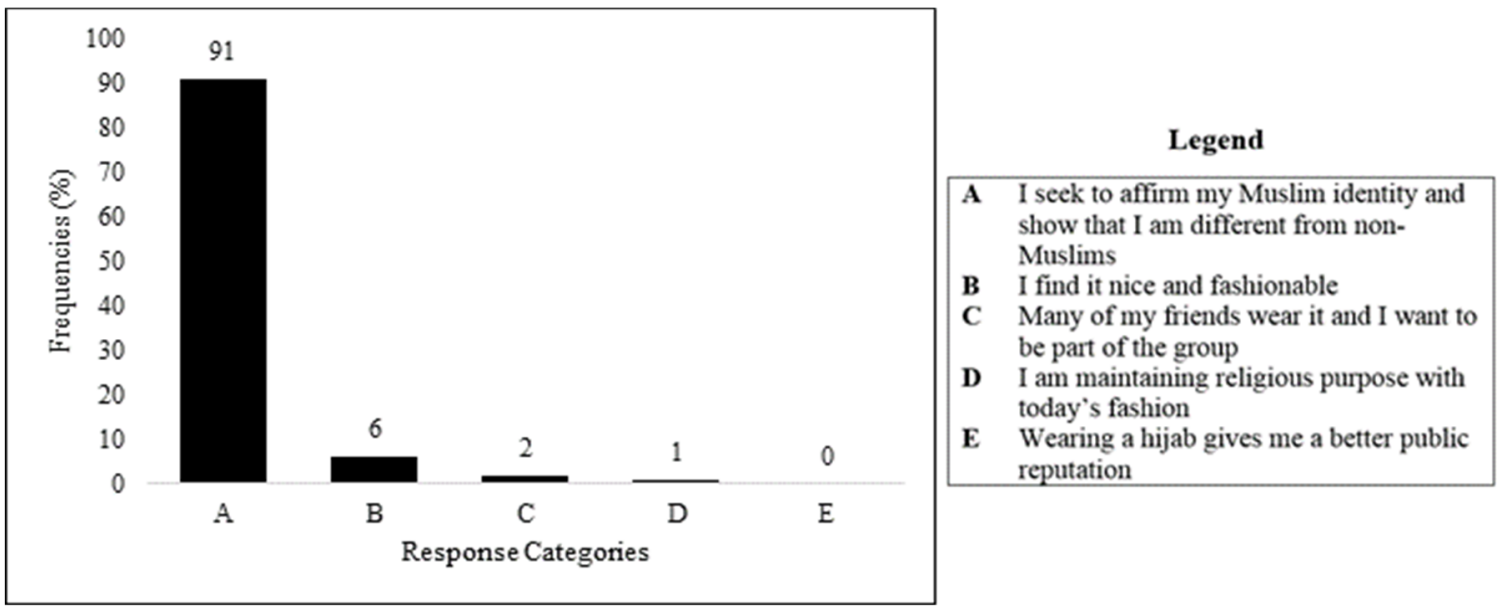

Source: Author's construct 


\subsection{Hijab with Fashionable Western Clothes}

This research found a significant correlation between wearing fashionable clothes and hijab. There are also variations in terms of preferences of how to use a hijab. Among the respondents, $72 \%$ prefer to wear hijab with fashionable clothes but on occasions only, and they do not always wear hijab. This might imply that ideal social self-images and actual self-images of most of the respondents are different because on occasions they are exposed to many people when they prefer to demonstrate their affinity for hijab which they do not do in other time when they are not exposed to many people. This also conforms to the collectivist social reality (Deci and Ryan 2008). Only $18 \%$ of the respondents prefer to wear hijab every time they wear fashionable western clothes which implies their similar priority for both hijab and fashionable western clothes. They seem to give similar priority for both personal and group senses where the Muslim dominated social norms can be associated with the development of group senses. It is noteworthy that $10 \%$ of the respondents never want to wear a hijab with fashionable western clothes. This implies that their senses of attire involving hijab and fashionable western clothes are not compatible.

\subsection{Fashion Trend of Hijab}

Almost all (97\%) the respondents argue that a fashion trend of wearing hijab is prevailing and only $3 \%$ of them disagree with it. Among those who agreed that there is a fashion trend for hijab, $46 \%$ are between $20-40$ years of age, $48 \%$ are between $40-60$ years of age, and $6 \%$ are below the age of 20 . This change in perception in different age groups may be caused by the scenario that in Bangladesh internet and digital technologies became pervasive in early 2000 which offered children at that time with enhanced exposure to cross-cultural global reality which, in this perspective, has been argued to be dominated by the middle east and the west. Among the respondents, 93\% believe that hijab fashion trend played an important role to positively influence their hijab buying behavior. This evidences the power of fashion and aesthetics in consumer buying behavior. However, $7 \%$ of the respondents who are relatively older and are of over 50 years do not identify the influence of fashion trends on their hijab buying behavior which might be explained by the understanding that mature consumers are less inclined towards changes and innovativeness (Lambert-Pandraud and Laurent, 2010).

Personalization of hijab by draping it in a certain way became a popular trend and it varies in different countries. Hijabistas not only drape hijab in a variety of stylish patterns but also combine multi-color and multilayer fabrics with gorgeous sparkly decorative accessories such as colorful hijab pins with glitter balls and/or stones, jewelry headpiece, floral wreath or headdress, and hair jewelry. This trend also indicates a strong connotation of fashion senses in wearing hijab as a fashion symbol. Among the respondents, $96 \%$ drape hijab in a personalized pattern and only $4 \%$ are indifferent of any draping pattern or trend. Among the respondents, $96 \%$ follow YouTube and other digital contents to learn different draping techniques which implicates that digital contents on different web platforms, particularly YouTube, are popular among hijab users. Leena, With love, Yowis Fariin, Parizaad Zaman, Aisha Liyana, and Noshin Nower are popular influencers in Bangladesh. Among the global hijab influencers, Yasmin Kanar, Manal Jalil, Dian Pilangi, Ruba Zai, and Imane Alasry are known to the respondents; $76 \%$ prefer Yasmin Kanar of USA, 17\% prefer Manal Jalil of Canada, 4\% prefer Dian Pilangi of Indonesia, $2 \%$ prefer Ruba Zai of the Netherlands, and 1\% prefer Imane Alasry of Sweden.

Majority respondents (82\%) consider hijab as a fashion item indicating acceptance of inclusion of fashion in Muslim attire. Only a few of them (3\%) believe that hijab is not a fashion item and even a fewer $(2 \%)$ percentage of the respondents believe that hijab must not be considered as a fashion item. These perspectives depict a liberal approach to fashion hold by the respondents when considered through the lens of Muslim attire. Figure 10 demonstrates relative perspectives of the respondents. 
Figure 10: Is Hijab a Fashion Item?

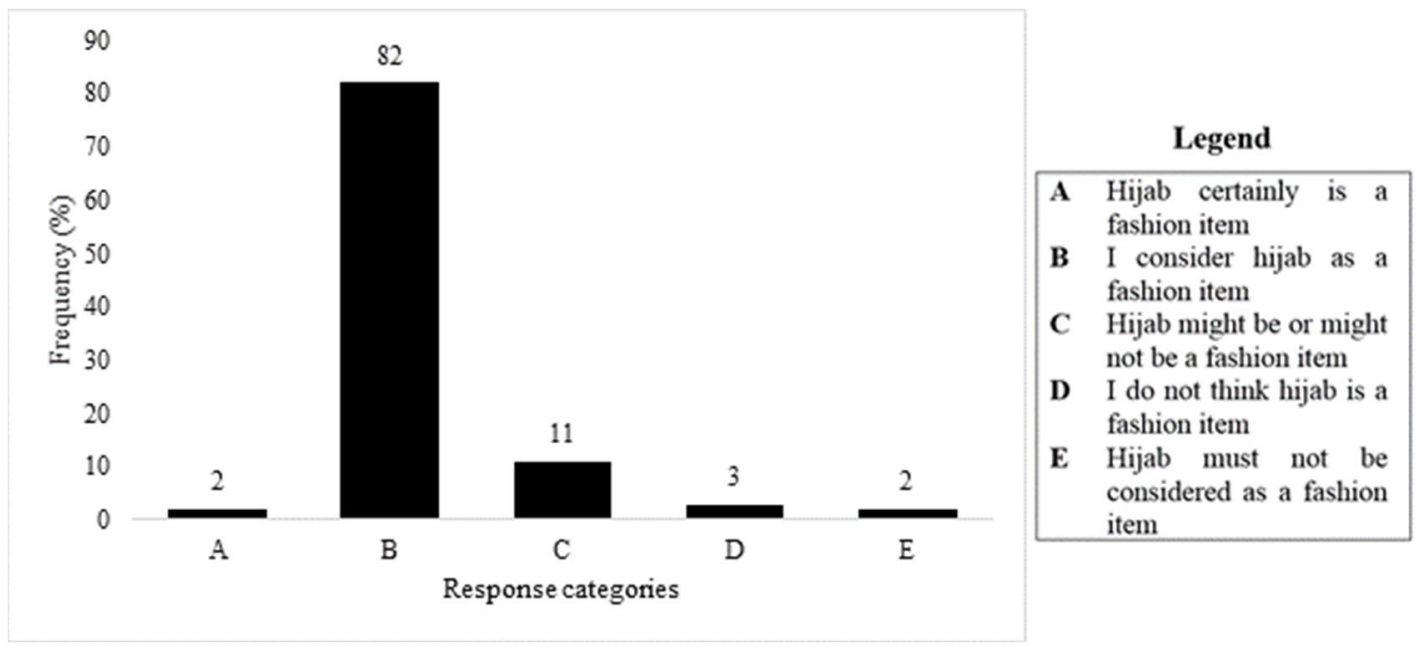

Source: Author's construct

Among the respondents, $54 \%$ believe that hijab undoubtedly enhances women's beauty. This evidences an important trait of majority of the hijabi women's understanding of beauty and their preference of the means of enhancing beauty. It also shows the strong influence of a tangible attire on the prevailing senses about beauty which is an important input for designers and marketers who target hijabi women. $43 \%$ of the respondents believe that hijab can enhance women's beauty. Only a minority of the respondents think otherwise. Only $2 \%$ respondents claim that hijab is not always the reason for enhancement of beauty and $1 \%$ respondents preserve a conviction that hijab does not enhance beauty. These findings show a dominant trend among the hijabi women and indicates a direction of the dynamism in fashion senses. Figure 11 demonstrates this trend with respective data.

Figure 11: Does Hijab Enhance Beauty?

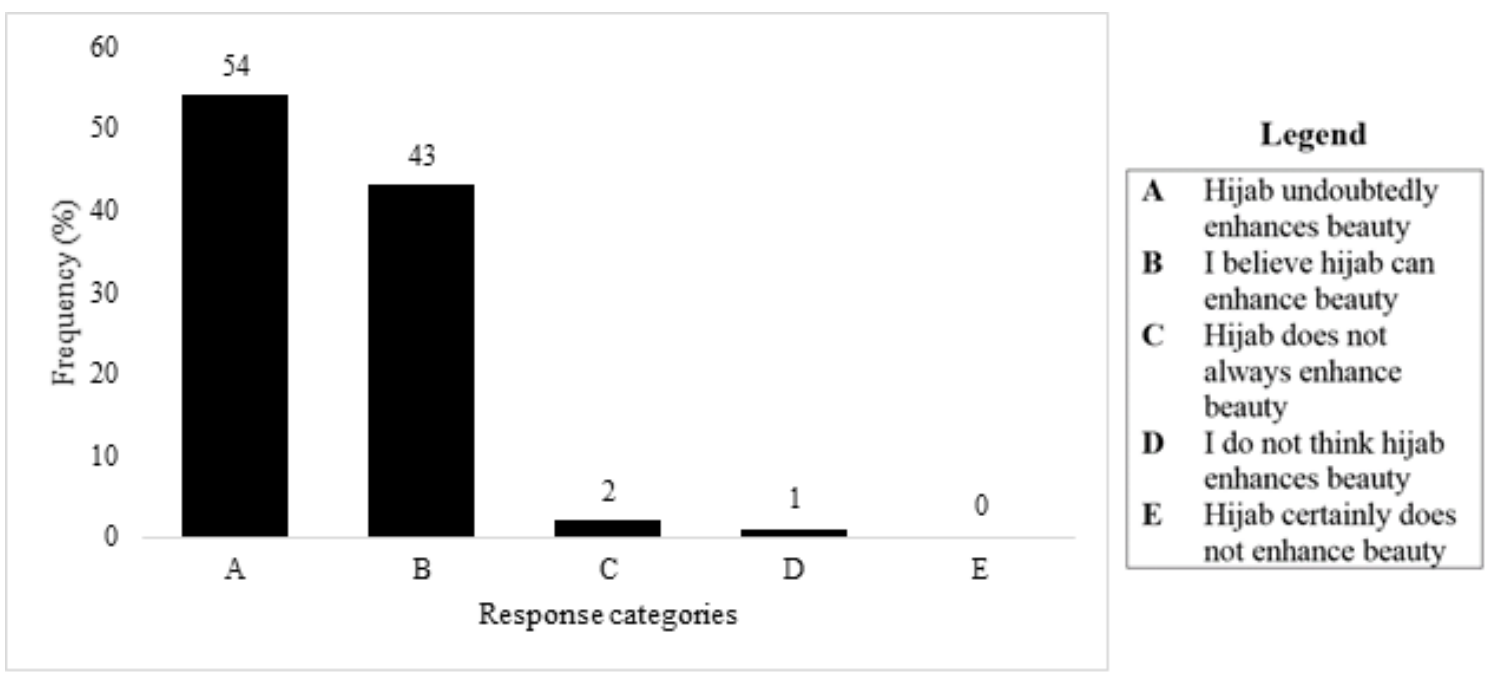

This research identifies that even though Bangladeshi Muslim women start wearing hijab with the initial motivation from Islamic dress code, gradually they find other stimuli such as attractive hijab influencers, related contents, and representations of hijab by globally esteemed magazines that reinforces their devotion to wear hijab. However, only $5 \%$ of the respondents wear hijab solely for religious purposes whereas $92 \%$ of them wear hijab because of two prominent reasons - maintaining religious dress code and belonging to the group of hijab fashion connoisseurs. The power of fashion in making hijab an inseparable part of identity for Muslim women is therefore quite strong. Only $3 \%$ of the respondents wear hijab only to protect their hair from air pollution. This scenario does not only depict the seriousness of the situation of air pollution in Bangladesh but also shows opportunities for marketers who deal in products that can offer benefits to those who are conscious about protecting their hair from pollution. First preferred hijab related information source is social networking sites and $97 \%$ use those to develop their knowledge. This also shows the reality that majority of the hijabistas and the group of people belonging to that age group can be reached digitally. The second preferred information and knowledge source is 
catalogs for $55 \%$ of the respondents. The third preferred sources are fashion magazines and fashion shows for $30 \%$ of the respondents. The least priority is with salesperson and sales fairs which only $4 \%$ of the respondents consider as information sources.

\section{Conclusions}

Hijab can be just a commitment to one's religious beliefs and in that case, it is supposed to be an attire with the minimal design involvement, maximum adherence to religious dress code, and comfort. However, Hijab can also be exotic, attractive, provocative, impressive, and self-uplifting. In this case, it is fashion wear. Hijab sometimes can be oppressive, self-limiting, and compelling; making it a barrier for women's progression; so true meaning of hijab is diverse and deep-rooted. Not everyone wears a hijab for the same reason. Some adopt hijab for a religious purpose while others adopt it due to family imposition and/or force, social oppression, and to be a part of the group of hijab fashion connoisseur. Increased number of Islamic followers around the world has escalated Islamic consumerism and compliant lifestyle through modest clothing. Growth of hijab fashion created a lucrative modest fashion industry in Bangladesh.

Wearing a hijab was a rare phenomenon in Bangladesh in the 1970s, and the habit was gradually adopted by a few during the 1990s and 2000s and became a prominent fashion trend in the last decade. The factors play significant roles in increasing popularity of hijab among women include fashion consciousness compatible with religious values, marketing initiatives, influence of opinion leaders and influencers, desire for enhancement of beauty, and globalization. Religious directive and commitment have the strongest influence on the decision to wear a hijab. Muslim women are now socially more engaged mostly due to increased involvements in education, career focused attitude, and effects of globalization. They now have a stronger demand for clothing which ensures modesty, beauty, fashion, and acceptance. Young Muslim women are highly influenced by opinion leaders such as youth icons, celebrities, teachers, friends, and family members who have adopted Muslim attire and have earned credibility and acceptance in respective societies. A considerable number of digitally connected young Muslim hijabistas are motivated by YouTube contents which promote Muslim attire. Bangladeshi hijabistas wear hijab following various creative styles. Businesses are incorporating this hijab trend by presenting hijabi models in advertisements and offering new products and services with notions of fashion senses through hijab. It can be argued that women in Bangladesh have formed a positive attitude towards hijab as it can help them balance Islamic values with senses of fashion. The increasing popularity and adoption of hijab has become an explicit evidence that hijab is perceived as a Muslim attire that can offer women an identity and the respective fashion trend has been reinforcing the perception.

\section{References}

Ahmed, N. (2020). “Gala Makeover Studio \& Salon”, available at: http://galabd.com/ (accessed 3 September 2020). Al-Ardhi, M.M. (2008). Arabs: Down Under, South Street Press, Garnet Publishing, UK.

Ali, S. (2005). "Why here, why now? Young Muslim women wearing hijab", The Muslim World, Vol. 95 No. 4 , pp.515-530.

Almila, A.M. and Inglis, D. (2019). The Routledge International Handbook to Veils and Veiling, Taylor and Francis Group, London.

Audriana (2020). “Audriana: Nazia Hassan Signature”, available at: https://www.facebook.com /audrianaexclusives/ (accessed 9 September 2020).

Auty, S.G. and Elliott, R. (2001). "Being like or being liked: Identity vs. approval in a social context", Advances in Consumer Research, Vol. 28 No. 1, pp.235-241.

Bohdanowicz, J. and Clamp, L. (1994). Fashion Marketing, Routledge, London.

Blommaert, J. and Varis, P. (2015). "Culture as accent: the cultural logic of Hijabistas", Semiotica, Vol. 203, pp.153-177.

Burns, D.J. and Warren, H.B. (1995). "Need for uniqueness: shopping mall preference and choice activity", International Journal of Retail and Distribution Management, Vol. 23 No. 12, pp.4-12.

Cardoso, P.R., Costa, H.S. and Novais, L.A. (2010). "Fashion consumer profiles in the Portuguese market: involvement, innovativeness, self-expression, and impulsiveness as segmentation criteria", International Journal of Consumer Studies, Vol. 34 No. 6, pp.638-647.

Carrington D. and Taylor, M. (2018). "Air pollution is the 'new tobacco', warns WHO head", available at: https://www.theguardian.com/environment/2018/oct/27/air-pollution-is-the-new-tobacco-warns-who-head (accessed 10 September 2020).

Cinar, A. (2005). Modernity, Islam, and secularism in Turkey: bodies, places, and time, University of Minnesota Press, USA.

Dagkas, S. and Benn, T. (2006). "Young Muslim women's experiences of Islam and physical education in Greece and Britain: a comparative study", Sport, Education and Society, Vol. 11 No. 1, pp.21-38.

Deci, E.L. and Ryan, R.M. (2008). "Hedonia, eudaimonia, and well-being: an introduction", Journal of Happiness 
Studies, Vol. 9, pp.1-11.

Dhaka Tribune (2020). "Dhaka ranks worst in air quality index", available at: https:// www.dhakatribune.com/bangladesh/dhaka/2020/02/09/dhaka-ranks-worst-in-air-quality-index-2-2 (accessed 10 September 2020).

Ehren, L. (n.d.). "Hijabi bloggers we love following", available at: https://www.myus.com/blog/hijabi-bloggerswe-love-following/ (accessed 6 August 2020).

El Guindi, F. (1981). "Veiling Infitah with Muslim Ethic: Egypt's Contemporary Islamic Movement", Social Problems, Vol. 28 No. 4, pp.465-485.

El Guindi, F. (1999). "Veiling resistance, Fashion Theory", The Journal of Dress, Body, and Culture, Vol. 3 No. 1, pp.51-80.

El Guindi, F. (2003). Veil: Modesty, Privacy and Resistance, Bloomsbury, Oxford.

El Guindi, F. (2020). By noon prayer: The rhythm of Islam, Routledge, London and New York.

Fanon, F. (1965). A Dying Colonialism, Grove Press, New York.

Fatema, M. and Islam, M.A. (2014). "A conceptual framework on the study of trends of Islamic fashion and clothing practices amongst young Muslim female in Bangladesh", Advances in Environmental Biology, Vol. 8 No. 9, pp.715-719.

Fernandez, C. (2016). "How should designers approach creating fashion for Muslim women?" available at: https://fashionista.com/2016/04/pierre-berge-muslim-fashion (accessed 13 August 2020).

Galadari, A. (2012). "Behind the Veil: Inner Meanings of Women's Islamic Dress Code", The Journal of Interdisciplinary Social Sciences, Vol. 6 No. 11, pp.115-125.

Genel, S. and Karaosmanoglu, K. (2006). "A new Islamic individualism in Turkey: Headscarfed women in the city”, Turkish Studies, Vol. 7 No. 3, pp.473-488.

Glamour (2017). "American Eagle is now selling denim hijabs", available at: https://www. glamour.com/story/american-eagle-selling-denim-hijabs (accessed 21 August 2020).

Glamour (2018). "H\&M introducing a modest fashion line for Spring", available at: https://www.glamour.com/ story/hm-modest-fashion-line (accessed 21 August 2020).

Gordon, G. (2018). "8 Brands you would never consider for your Ramadan wardrobe (until now)", available at: https://www.savoirflair.com/fashion/383172/ramadan-2018 (accessed 23 August 2020).

Gutman, J. and Mills, M.K. (1982). "Fashion life-style, self-concept, shopping orientation, and store patronage: an integrative analysis", Journal of Retailing, Vol. 58 No. 2, pp.64-86.

Hassan, S.H. and Harun, H. (2016). "Factors influencing fashion consciousness in hijab fashion consumption among hijabistas", Journal of Islamic Marketing, Vol. 7 No. 4, pp.476-494.

Hassim, N. (2014). "A comparative analysis on hijab wearing in Malaysian Muslimah magazines", The Journal of South East Asia Research Centre for Communications \& Humanities, Vol. 6 No. 1, pp.79-96.

Hassim, N., Nayan, S.M. and Ishak, M.S.A. (2017). "Hijabistas: An Analysis of the Mediation of Malay-Muslims and Modesty”, Malaysian Journal of Media Studies, Vol. 17 No. 2, pp.10-25.

Hawkins, D.I. and Mothersbaugh, D.L. (2010). Consumer Behavior: Building Marketing Strategy, McGraw-Hill Irwin, New York.

Hussain, N.J. (2020a). "nadiyajhussain", available at: https://www.instagram.com/nadiyajhussain/?hl=en (accessed 12 August 2020).

Hussain, N.J. (2020b). Time to Eat: Delicious Meals for Busy Lives, Michael Joseph, USA.

Ibrahim, N.A., Ghazali, Z. and Zakaria, Z. (2011). "The influence of socialization agents on fashion consciousness", International Journal of Business and Social Science, Vol. 2 No. 14, pp.127-134.

Irfan, A. (n.d.). "The women breaking hijab fashion boundaries", Readers Digest, available at: https://www.readersdigest.co.uk/lifestyle/fashion-beauty/the-women-breaking-hijab-fashion-boundaries (accessed 27 November 2020).

Jin, B. and Son, J. (2013). "Face saving, materialism, and desire for unique apparel products: differences among three Asian countries", The Journal of the Textile Institute, Vol. 105 No. 3, pp.304-313.

Kavakci, E. and Kraeplin, C.R. (2016). "Religious beings in fashionable bodies: the online identity construction of hijabi social media personalities", Media, Culture \& Society, Vol. 39 No. 6, pp.850-868.

Kinley, T., Conrad, C. and Brown, G. (2000). "Personal versus non-personal sources of information used in purchase of men's apparel", Journal of Consumer Studies - Home Economics, Vol. 24 No. 1, pp.67-73.

Koç, E., Taşkın, Ç., and Boz, H. (2019). "Risk and Control in Consumer Behavior: A Discussion", Grima, S., Özen, E., Boz, H., Spiteri, J. and Thalassinos, E. (Ed.), Contemporary Issues in Behavioral Finance, Emerald Publishing, UK, pp.1-12.

Lambert-Pandraud, R. and Laurent, G. (2010). "Why do older consumers buy older brands? The role of attachment and declining innovativeness", Journal of Marketing, Vol. 74 No. 5, pp.104-121.

Latiff, Z.A. and Alam, F.N.S.Z. (2013). "The roles of media in influencing women wearing hijab: An analysis", Journal of Image and Graphics, Vol. 1 No. 1, pp.50-54. 
Lewis, R. (2013). “Hijab stories: choice, politics, fashion”, In Bruzzi, S. and Gibosn, P.C. (Eds.) Fashion cultures revisited, Routledge, London and New York, pp.305-321.

Lifestyle (2018). “'We respect all religions, all cultures': Dolce \& Gabbana sends headscarves and saris down the runway", available at: https:/www.thenational.ae/lifestyle/luxury/we-respect-all-religions-all-culturesdolce-gabbana-sends-headscarves-and-saris-down-the-runway-1 (accessed 20 August 2020).

Lynn, M. and Harris, J. (1997). "The desire for unique consumer products: A new individual differences scale", Psychology \& Marketing, Vol. 14 No. 6, pp.601-616.

Macy's (2020). "Verona collection Jersey hijab", available at: https:/www.macys.com/shop/product/ veronacollection-jersey-hijab?ID=5891539 (accessed 11 September 2020).

Milewski, J.A. (2005). "Fashion and the culture of consumption perceptions of fashion trends among college students”, available at: https://www.asanet.org/sites/default/files/am_2005_annual_meeting_final_ program.pdf (accessed 13 September 2020).

Mossiere, G. (2012). "Modesty and style in Islamic attire: refashioning Muslim garments in a Western context", Contemporary Islam, Vol. 6 No. 2, pp.115-134.

Mostafa, M. (2020). "10 Hijabi influencers to look out for in 2019”, available at: https://blog.hautehijab. com/post/10-hijabi-influencers-to-look-out-for-in-2019 (accessed 26 August 2020).

Mullen, B. and Johnson, C. (1990). "Distinctiveness-based illusory correlations and stereotyping: a meta-analytic integration", British Journal of Social Psychology, Vol. 29 No. 1, pp.11-27.

Nam, J., Hamlin, R., Gam, H.J., and Hye, K.J. (2007). "The fashion-conscious behaviors of mature female consumers", International Journal of Consumer Studies, Vol. 31 No. 1, pp.102-108.

Nike (2017). "The Nike pro hijab goes global", available at: https://news.nike.com/news/nike-pro-hijab (accessed 26 September 2020).

O'Cass, A., Lee, W.J. and Siahtiri, V. (2013). "Can Islam and status consumption live together in the house of fashion clothing?", Journal of Fashion Marketing and Management, Vol. 17 No. 4, pp.440-459.

Okwodu, J. (2019). "Halima Aden just became Sports Illustrated's first hijabi rookie", available at: https://www.vogue.com/article/halima-aden-sports-illustrated-rookie-first-model-in-hijab （accessed 20 August 2020).

Piacentini, M. and Mailer, G. (2014). "Symbolic consumption in teenager clothing choices", Journal of Consumer Behaviour, Vol. 3 No. 3, pp.251-262.

Posts, C. (2018). "Recent report of modest fashion influence at the global Islamic economy", available at: https://goltune.com/report-of-modest-fashion-influence-in-the-world/ (accessed 14 September 2020).

Potts, J. (2009). Lifting the Veil on Fashion: Filling the Gaps Between Modesty and Fashion Apparels, Ohio State University, USA.

Rahman, S.M., Islam, M.N., and Ferdousi, A. (2018). "Is hijab a fashion statement? A study on Bangladeshi Muslim women”, Journal of Business and Management, Vol. 20 No. 12, pp.21-27.

Rita, A.A. (2017). "Assertion of wearing hijab in the community: an analysis", American Scientific Research Journal for Engineering, Technology, and Sciences, Vol. 29 No. 1, pp.340-347.

Siraj, A. (2011). "Meanings of modesty and the hijab amongst Muslim women in Glasgow, Scotland", Gender, Place \& Culture, Vol. 18 No. 6, pp.716-731.

Sonbuol, L.Y. (2017). The Real Face of Arabic Symbols, Thesis, Rochester Institute of Technology, USA.

Schiffman, L.G. and Kanuk, L.L. (2010). Consumer behavior, Pearson Education, USA.

Stacey, A. (2009). "Why Muslim women wear the veil, The Religion of Islam", available at: https://www. islamreligion.com/articles/2770/why-muslim-women-wear-veil/ (accessed 12 August 2020).

Tarlo, E. (2010). "Hijab online: the fashioning of cyber Islamic commerce", Interventions, Vol. 12 No. 2, pp.209225.

Tarlo, E. (2020). "Islamic Fashion Scape”, In Barnard, M. (Ed.) Fashion Theory: A Reader, Routledge, London and New York, pp.374-388.

Thomson Reuters (2018). An Inclusive Ethical Economy - State of the Global Islamic Economy Report - 2018/19, Thomson Reuters, UAE.

Tian, K.T., Bearden, W. and Hunter, G. (2001). "Consumers' Need for Uniqueness: Scale Development and Validation”, Journal of Consumer Research, Vol. 28 No. 1, pp.50-66.

Vogue (2017). "Superstar singer Yuna is engaged", available at: https://en.vogue.me/culture/ hijabi-singer-yunaengaged/ (accessed 9 August 2020).

Vogue (2018). "9 trailblazing models cover may vogue", available at: https://www.vogue.co. uk/article/may-covervogue-2018 (accessed 9 August 2020).

Vogue (2019). "Hijabi Cover Stars Highlight the Power of Choice and What Modesty Means Today", available at: https://en.vogue.me/fashion/hijabi-vogue-arabia-april-2019-cover-stars-the-power-of-choice/ (accessed 9 August 2020).

Vogue (2020). "Meet the 3 essential workers on the cover", available at: https://www.vogue. 
co.uk/news/article/keyworkers-july-2020-issue-british-vogue (accessed 9 August 2020).

Wan, F., Youn, S., and Fang, T. (2007). "Passionate surfers in image-driven consumer culture: fashion consciousness, appearance savvy people and their way of life", Advances in Consumer Research, Vol. 28 No. 1, pp.266-274.

Wilson, J.A.J. (2014). "Inconspicuous branded consumption is the new business buzzword in retail", available at: https://www.huffingtonpost.co.uk/jonathan-aj-wilson (accessed 14 September 2020).

Wilson, J.A.J. and Liu, J. (2011). "The challenges of Islamic branding: navigating emotions and halal", Journal of Islamic Marketing, Vol. 2 No. 1, pp.28-42.

Zaman, P. (2020). "Pari ZaaD", available at: https://www.youtube.com/channel/UCwKw07KTu RhtkaIlH8gPsdg (accessed 24 August 2020). 